\title{
Public health measures during an anticipated influenza pandemic: Factors influencing willingness to comply
}

\author{
Melanie Taylor' \\ Beverley Raphael' \\ Margo Barr ${ }^{2}$ \\ Kingsley Agho' \\ Garry Stevens' \\ Louisa Jorm' \\ 'School of Medicine, University \\ of Western Sydney, Sydney, Australia; \\ ${ }^{2}$ Centre for Epidemiology \\ and Research, New South Wales \\ Department of Health, Sydney, \\ Australia
}

\begin{abstract}
This research assessed factors associated with willingness to comply with vaccination, isolation, and face mask wearing during an anticipated influenza pandemic. Data were collected from 2081 adults (16+) using a module of questions incorporated into the NSW Health Adult Population Health Survey. High levels of willingness to comply were reported with $73 \%$ either very or extremely willing to receive vaccination, $67 \%$ willing to isolate themselves, $58 \%$ willing to wear a face mask, and $48 \%$ willing to comply with all three behaviors. Further analysis indicated concern for self and family and higher levels of education were associated with high levels of willingness to comply. Younger people (16-24) were the least willing to comply; especially with wearing a face mask. Those with children reported higher levels of willingness to receive vaccination, and respondents who speak a language other than English at home were less willing to isolate themselves or comply with all behaviors. These findings provide a baseline measure of anticipated public compliance with key public health behaviors in the event of an influenza pandemic in the Australian population, and help to identify groups that may be more resistant to individual measures and may require additional attention in terms of risk communication strategies or health education.
\end{abstract}

Keywords: risk perception, pandemic influenza, compliance, health behaviors

\section{Introduction}

Willingness of the general public to comply with protective public health measures in the event of pandemic influenza is necessary for success in disease response and containment. In addition, better estimates of population compliance with such measures is valuable when assessing their contributions in the mathematical modeling of pandemics and in estimating the effectiveness of pandemic control decisions and policies; both in terms of disease containment and cost. A recent systematic review of physical interventions to reduce the spread of respiratory diseases ${ }^{1}$ has clearly demonstrated the significant contribution of simple low-cost interventions, such as mask-wearing and hand washing. Data in this review, from severe acute respiratory syndrome (SARS)-related studies, indicated that mask-wearing reduced risk of spread by $68 \%$; a figure that increased to $91 \%$ if N95 masks were worn.

Review of the Australian Management Plan for Pandemic Influenza ${ }^{2}$ and the NSW state health action plan ${ }^{3}$ suggests that the need for the general population to wear face masks is likely to be a key component in ensuring continuity of essential services (eg, public needing to wear face masks in health care settings), and in supporting societal functioning (eg, people wearing face masks on public transport or when in common public areas such as shops/malls). Where possible, the continuation of daily activities is likely to be important for population mental health as well as commercial and economic resilience. 
Vaccination has been identified in the Australian plan and by the World Health Organization (WHO) as a potential strategy in the early response to pandemic influenza, and hence, population willingness to receive vaccination is an important factor for consideration. State pandemic vaccination plans promote use of pneumococcal vaccination and inter-pandemic (or seasonal) influenza vaccine for priority and at-risk groups, and the WHO has recommended seasonal influenza vaccinations for health care workers to reduce risks of genetic shifts in the avian influenza virus and to minimize "background noise" in the event of an outbreak. ${ }^{4}$ Pandemicstrain vaccination may take a number of months to supply in sufficient quantities for population-level vaccination, however, if there was sufficient lag in the global spread of influenza to Australia a widespread mass vaccination of the population could become a key preventative national strategy. Willingness to go into isolation or quarantine (either voluntarily or compulsorily) may also become a requirement of the containment strategy at state and national levels.

\section{Studies of public health compliance during SARS and avian influenza outbreaks}

A number of studies relating to public compliance with protective health behaviors have been published in recent years; including either reported levels of compliance during the outbreaks of SARS and H5N1/avian influenza, or in anticipation of an H5N1/avian influenza pandemic.

Studies relating to behavior during or around SARS outbreaks in Hong Kong indicated that during SARS more than $90 \%$ of Hong Kong residents frequently wore face masks., Following SARS it was reported that $71 \%$ would wear face masks if there was a resurgence of SARS. ${ }^{6}$ However, research in Singapore during SARS found that only $4 \%$ of respondents in a representative population sample had worn a face mask in the preceding three days. ${ }^{7}$ SARS-related research from Toronto, Canada focused on compulsory quarantine and voluntary quarantine/isolation, mostly in health care workers rather than in the general population. ${ }^{8,9}$ Compliance with compulsory quarantine was reported as high. ${ }^{9}$ In population research fear of job/income loss was one of the most common reasons for noncompliance or for not self-quarantining. ${ }^{8}$ In addition, the importance of good social support (friends/family) was identified, due to high reliance on others for groceries and routine supplies; a need which the Government was unable to meet.

Studies of anticipated general population compliance with protective behaviors have been undertaken in Hong Kong, ${ }^{10,11}$ Norway, ${ }^{12}$ Italy,${ }^{13}$ the USA,${ }^{14}$ and, comparatively, across a number of European and Asian countries. ${ }^{15}$ In the small USA study ${ }^{14}$
$82 \%$ of participants reported that they would wear a face mask to protect others if they caught avian flu, $78 \%$ would accept quarantine, and $84 \%$ reported that they would want vaccine to protect them from avian flu if it were available. In the comparative Europe/Asia study, ${ }^{15} 45 \%-52 \%$ would limit contact with family and friends, and $24 \%-35 \%$ would stay indoors. In Hong Kong $73.8 \%$ of respondents reported that they would wear a mask in public venues and $88.3 \%$ reported that they would be fully compliant with any quarantine policies. ${ }^{10}$

Factors influencing uptake of protective behaviors were reported in many studies of SARS, and avian influenza, with increased compliance often being associated with higher risk perception and anxiety, ${ }^{16}$ concern for self/family/children, ${ }^{10,16}$ perceived susceptibility, ${ }^{17,18}$ greater knowledge regarding transmission, ${ }^{13}$ and perceived effectiveness of protective measures. ${ }^{10}$ With regard to demographic factors, increased adherence to protective behaviors is often associated with older age groups, female gender, higher levels of education, ${ }^{10,16}$ and being in full time employment. ${ }^{10}$

Studies specifically concerning willingness to receive vaccination in the event of a future outbreak of H5N1/avian influenza or in relation to SARS have not been found in Australia or other countries not previously affected by SARS or H5N1, However, Australian data relating to population willingness to receive seasonal influenza exists, and suggests that for those in influenza risk groups (over $65 \mathrm{~s}$, and 40s-64s meeting established research council (NH\&MRC) 'at risk' criteria) influenza vaccination uptake is influenced by perceptions of risk, self rated health status and beliefs about the efficacy of the vaccination. ${ }^{19}$ Data from Hong Kong indicate that rates of seasonal influenza vaccination have increased since SARS and H5N1 and vaccination uptake behavior was linked to higher perceived likelihood of a large local outbreak of $\mathrm{H} 5 \mathrm{~N} 1$ in the future and perceptions that any future outbreak would be worse than SARS had been. ${ }^{17}$

The purpose of the current study was to gather the first baseline Australian data on public levels of willingness to comply with vaccination, isolation, and face mask wearing in the event of an influenza pandemic in Australia, and to assess a selection of sociodemographic, health, and threat perception factors that might influence such decisions.

\section{Methods}

A short six item pandemic influenza question module was developed, as the first part of a larger module of questions on potential threats. These questions were field tested, validated and subsequently administered within the NSW Population Health Survey, using the NSW Health Survey program CATI 
system, between January 22nd and March 31st, 2007. The NSW population health survey includes questions on health behaviors, health status (including psychological distress, using the Kessler 10 measure, ${ }^{20}$ and self-rated health status), access to health services, as well as the demographics of the respondents and the households. The target sample was persons living in NSW stratified by the state's eight area health services. Households were contacted using random digit dialing. Details of the sampling approach can be found in the 2007 NSW Health survey report. ${ }^{21}$

\section{Question module}

The pandemic influenza question module comprised three questions addressing pandemic influenza threat perception and three questions addressing willingness to comply with requested protective health behaviors. The latter questions are the subject of this paper, and their wording was as follows:

"In case of an emergency situation, government authorities might request co-operation from the public in a number of ways. Please indicate ..."

1. How willing would you be to receive vaccination?

2. How willing would you be to isolate yourself from others if needed?

3. How willing would you be to wear a face mask?

All responses were coded on a five-point Likert-scale. Response options for all questions were 'not at all willing,' 'a little willing,' 'moderately willing,' 'very willing,' and 'extremely willing'. In addition, 'don't know' and 'refused' responses were coded.

The remaining pandemic influenza questions on threat perception included a question on how likely respondents thought it was that there would be an influenza pandemic in Australia, how concerned they would be that they or their family would be affected by such a pandemic, and whether they had made changes to their life because of the possibility of an influenza pandemic. Prevalence data for these questions has been reported by Barr and colleagues. ${ }^{22}$ In this study, the threat perception questions were used as independent variables in the analysis to assess whether aspects of threat perception influenced anticipated compliance.

\section{Data analysis}

The survey data were weighted to adjust for probability of selection and for differing response rates among males and females and different age groups. ${ }^{21}$ Data analysis was performed using the "SVY" commands of Stata version 9.2 (Stata Corp, College Station, TX, USA), which allowed for adjustments for sampling weights.
The five-point Likert-scale response used in the question module were dichotomized, such that responses of very/ extremely willing (high willingness) were coded as 1 and all other responses as 0 . In addition a composite 'all' measure was calculated in which data from respondents who indicated that they would be very/extremely willing to comply with all three behaviors had their response coded as 1 and those with willingness to comply with two or fewer behaviors were coded as 0 . This enabled identification and analysis of a group in the sample that reported high universal willingness to comply.

To assess the factors that influence willingness to comply with protective health behaviors, the dichotomized compliance question indicators and the 'all' indicator were used as outcome measures and these were investigated using the following set of independent variables: gender; age; marital status; have children; location (urban/rural) as defined by respondents' area health region; born in Australia; speak a language other than English at home; living alone; employed; highest level of formal education; household income; self-rated health status; psychological distress (as determined by the Kessler K10 measure, which is a composite measure with a range of 10-50 in which 'high psychological distress' has been categorized as a score ? 22 and 'low psychological distress' as a score $<22$ ); ${ }^{20}$ and the three pandemic influenza threat questions (concern for self/family, pandemic likely, and life changes).

Multiple survey logistic regression using a stepwise backwards model was used in order to identify the factors significantly associated with willingness to comply with health protective behaviors. All variables with statistical significance of $\mathrm{p} \leq 0.05$ were retained in the final model.

\section{Results}

In total 2081 state residents aged 16 and over completed the module on pandemic influenza. The overall response rate was $65 \%$. The key demographics of the weighted survey were comparable to Australian Bureau of Statistics (ABS) 2006 Australian population census data. ${ }^{22}$

Overall $73 \%$ of the population indicated that they would be very or extremely willing to receive vaccination, $67 \%$ would be very/extremely willing to isolate from others if needed, 58\% would be very/extremely willing to wear a face mask, and $48 \%$ would be very/extremely willing to do all three. Less than $8 \%$ of the population reported being 'not at all' willing to wear a face mask, and considerably lower proportions of the population were 'not at all' willing to comply with vaccination $(3 \%)$ and isolation $(5 \%)$.

Tables 1A-D present results of the survey logistic regression modeling, showing the unadjusted and adjusted odds 
Table IA Survey logistic modelling of extremely/very willing to receive vaccination: unadjusted and adjusted odds ratios (OR)

\begin{tabular}{|c|c|c|c|c|c|c|c|c|}
\hline \multirow[t]{3}{*}{ Independent variable } & \multicolumn{8}{|c|}{ Extremely/very willing to receive vaccination } \\
\hline & \multicolumn{4}{|c|}{ Unadjusted } & \multicolumn{4}{|c|}{ Adjusted } \\
\hline & OR & $95 \% \mathrm{Cl}$ & & P value & OR & $95 \% \mathrm{C}$ & & Pvalue \\
\hline \multicolumn{9}{|l|}{ Gender } \\
\hline Male & 1.00 & - & - & - & - & - & - & - \\
\hline Female & 0.92 & 0.69 & 1.23 & 0.565 & - & - & - & - \\
\hline \multicolumn{9}{|c|}{ Location (defined by health region) } \\
\hline Urban & 1.00 & - & - & - & - & - & - & - \\
\hline Rural & 1.19 & 0.91 & 1.56 & 0.197 & - & - & - & - \\
\hline \multicolumn{9}{|c|}{ High psychological distress (K I0 ? 22) } \\
\hline No & 1.00 & - & - & - & - & - & - & - \\
\hline Yes & 0.92 & 0.53 & 1.60 & 0.774 & - & - & - & - \\
\hline \multicolumn{9}{|l|}{ Age } \\
\hline $16-24$ & 1.00 & - & - & - & 1.00 & - & - & - \\
\hline $25-34$ & 1.27 & 0.70 & 2.30 & 0.435 & 0.87 & 0.41 & 1.82 & 0.705 \\
\hline $35-44$ & 1.86 & 1.06 & 3.28 & 0.031 & 0.98 & 0.49 & 1.97 & 0.958 \\
\hline $45-54$ & 1.70 & 1.00 & 2.88 & 0.049 & 1.26 & 0.63 & 2.49 & 0.514 \\
\hline $55-64$ & 1.52 & 0.91 & 2.54 & 0.112 & 1.40 & 0.71 & 2.77 & 0.328 \\
\hline $65-74$ & 2.15 & 1.27 & 3.63 & 0.004 & 2.83 & 1.39 & 5.77 & 0.004 \\
\hline $75+$ & 1.38 & 0.80 & 2.39 & 0.252 & 1.59 & 0.74 & 3.40 & 0.232 \\
\hline \multicolumn{9}{|l|}{ Children in household } \\
\hline No & 1.00 & - & - & - & 1.00 & - & - & - \\
\hline Yes & 1.57 & I.II & 2.21 & 0.011 & 1.67 & 1.10 & 2.54 & 0.017 \\
\hline \multicolumn{9}{|l|}{ Born in Australia } \\
\hline No & 1.00 & - & - & - & - & - & - & - \\
\hline Yes & 1.26 & 0.90 & 1.76 & 0.175 & - & - & - & - \\
\hline \multicolumn{9}{|c|}{ Speak language other than English } \\
\hline No & 1.00 & - & - & - & - & - & - & - \\
\hline Yes & 0.62 & 0.41 & 0.95 & 0.026 & - & - & - & - \\
\hline \multicolumn{9}{|l|}{ Living alone } \\
\hline No & 1.00 & - & - & - & - & - & - & - \\
\hline Yes & 0.85 & 0.64 & I.II & 0.234 & - & - & - & - \\
\hline \multicolumn{9}{|l|}{ Highest formal qualification } \\
\hline University degree/equivalent & 1.00 & - & - & - & - & - & - & - \\
\hline TAFE certificate/Diploma & 0.71 & 0.47 & 1.09 & 0.116 & - & - & - & - \\
\hline High school certificate & 0.66 & 0.41 & 1.06 & 0.086 & - & - & - & - \\
\hline School certificate & 0.60 & 0.40 & 0.90 & 0.013 & - & - & - & - \\
\hline None & 0.80 & 0.48 & 1.34 & 0.402 & - & - & - & - \\
\hline \multicolumn{9}{|l|}{ Employed (paid or unpaid) } \\
\hline No & 1.00 & - & - & - & - & - & - & - \\
\hline Yes & 1.09 & 0.82 & 1.45 & 0.569 & - & - & - & - \\
\hline \multicolumn{9}{|c|}{ Household income (before tax) } \\
\hline$<\mathrm{A} \$ 20 \mathrm{k}$ & 1.00 & - & - & - & 1.00 & - & - & - \\
\hline$A \$ 20-40 \mathrm{k}$ & 1.07 & 0.69 & 1.67 & 0.750 & 1.13 & 0.71 & 1.80 & 0.600 \\
\hline$A \$ 40-60 \mathrm{k}$ & 0.95 & 0.60 & 1.50 & 0.814 & 1.17 & 0.69 & 1.97 & 0.560 \\
\hline$A \$ 60-80 k$ & 1.52 & 0.85 & 2.73 & 0.161 & 1.92 & 1.02 & 3.64 & 0.045 \\
\hline$>\mathrm{A} \$ 80 \mathrm{k}$ & 1.77 & 1.13 & 2.76 & 0.013 & 2.24 & 1.30 & 3.87 & 0.004 \\
\hline
\end{tabular}


Table I A (Continued)

\begin{tabular}{|c|c|c|c|c|c|c|c|c|}
\hline \multirow[t]{3}{*}{ Independent variable } & \multicolumn{8}{|c|}{ Extremely/very willing to receive vaccination } \\
\hline & \multicolumn{4}{|c|}{ Unadjusted } & \multicolumn{4}{|c|}{ Adjusted } \\
\hline & OR & $95 \% \mathrm{Cl}$ & & Pvalue & OR & $95 \% \mathrm{C}$ & & P value \\
\hline \multicolumn{9}{|c|}{ Good self-rated health status } \\
\hline Yes & 1.00 & - & - & - & - & - & - & - \\
\hline No & 0.62 & 0.39 & 0.99 & 0.043 & - & - & - & - \\
\hline \multicolumn{9}{|l|}{ Marital status } \\
\hline Married & 1.00 & - & - & - & - & - & - & - \\
\hline Widowed & 0.64 & 0.43 & 0.94 & 0.023 & - & - & - & - \\
\hline Seperated/divorced & 0.88 & 0.57 & 1.34 & 0.540 & - & - & - & - \\
\hline Never married & 0.57 & 0.40 & 0.81 & 0.002 & - & - & - & - \\
\hline \multicolumn{9}{|c|}{ Pandemic influenza extremely/very } \\
\hline \multicolumn{9}{|c|}{ likely } \\
\hline No & 1.00 & - & - & - & - & - & - & - \\
\hline Yes & 1.39 & 0.90 & 2.13 & 0.138 & - & - & - & - \\
\hline \multicolumn{9}{|c|}{$\begin{array}{l}\text { Extremely/very concerned for self/family } \\
\text { in event of pandemic influenza }\end{array}$} \\
\hline No & 1.00 & - & - & - & 1.00 & - & - & - \\
\hline Yes & 2.60 & 1.90 & 3.57 & $<0.001$ & 2.90 & 2.00 & 4.21 & $<0.001$ \\
\hline \multicolumn{9}{|c|}{$\begin{array}{l}\text { Life changes due to possibility } \\
\text { of pandemic influenza }\end{array}$} \\
\hline No & 1.00 & - & - & - & - & - & - & - \\
\hline Yes & 0.92 & 0.64 & 1.32 & 0.645 & - & - & - & - \\
\hline
\end{tabular}

ratio (OR) for the associations between the three health protective behavior questions and the composite (All) indicator.

The influence of age on willingness to comply with protective behaviors was found to be a key variable, and this effect is illustrated in Figure 1.

\section{Discussion}

Generally, people reported high levels of willingness to comply with health protective behaviors in the event of pandemic influenza; with two thirds of the population reporting that they would be very/extremely willing to receive vaccination, two thirds reporting that they would be very/extremely willing to isolate if needed, and more than half reporting that they would be very/extremely willing to wear a face mask.

Although these indications of high willingness to comply may appear lower than expected, from other research studies, it should be noted that these data were collected at a time when pandemic influenza was not regarded as a high threat by Australians; only $14 \%$ of the NSW population reported that they felt pandemic influenza was very or extremely likely to occur. Evidence from other countries, as well as our multivariate analysis, suggest that general compliance with these behaviors would increase substantially if general concern increased, ${ }^{16}$ although other factors, such as access to face mask, social responsibility and social acceptance, perceived effectiveness, and communication strategies would also contribute.

Multivariate analysis of the data indicated that the factors associated with high willingness to comply varied with each behavior, although generally, those reporting higher levels of concern that they or their families would be affected by pandemic influenza and those with higher levels of formal education were more likely to report high willingness to comply, and those who were younger (especially in the 16-24 year old age group) were generally less likely to report high willingness to comply. The relative importance of these factors in public health measure compliance is consistent with the findings of others ${ }^{10,16}$ and provides helpful information to support those involved with risk communication and public health education.

Addressing individual behaviors, and in addition to the factors associated with high willingness to comply noted above, those with children and those with higher incomes were likely to report high willingness to receive vaccination. 
Table IB Survey logistic modelling of extremely/very willing to isolate if needed: unadjusted and adjusted odds ratios (OR) Independent variable Extremely/very willing to comply with Isolation

\begin{tabular}{|c|c|c|c|c|}
\hline Un & & & Adjusted & \\
\hline OR & $95 \% \mathrm{Cl}$ & $P$ value & $95 \% \mathrm{Cl}$ & P value \\
\hline
\end{tabular}

\section{Gender}

Male

Female

Location (defined by health region)

Urban

Rural

High psychological distress (K I 0 ? 22)

No

Yes

Age

16-24

25-34

35-44

45-54

55-64

65-74

$75+$

Children in household

No

Yes

Born in Australia

No

Yes

Speak language other than English

No

Yes

Living alone

No

Yes

Highest formal qualification

University degree/equivalent

TAFE certificate/Diploma

High school certificate

School certificate

None

Employed (paid or unpaid)

No

Yes

Household income (before tax)

$<\mathrm{A} \$ 20 \mathrm{k}$

A $\$ 20-40 \mathrm{k}$

A $\$ 40-60 \mathrm{k}$

A $\$ 60-80 k$

$>\mathrm{A} \$ 80 \mathrm{k}$

$\begin{array}{llll}1.22 & 0.93 & 1.60 & 0.155\end{array}$

1.00

I.2 |

0.94

1.56

0.133

$$
1.00
$$

0.76

0.46

1.28

0.305

$\begin{array}{llll}1.00 & - & - & - \\ 1.14 & 0.66 & 1.98 & 0.633 \\ 1.98 & 1.15 & 3.41 & 0.013 \\ 1.86 & 1.12 & 3.07 & 0.016 \\ 2.36 & 1.42 & 3.93 & 0.001 \\ 1.99 & 1.22 & 3.26 & 0.006 \\ 1.81 & 1.05 & 3.12 & 0.032\end{array}$

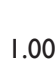

I. 13

0.83

1.00

I.39

I.0I

1.92

1.00

0.41

$-$

0.28

$-$

0.61

$<0.001$

1.00

0.37

0.24

0.57

$<0.001$

1.00

1.00

0.76

I.3I

0.994

1.00

0.93

0.67

0.64

0.64

$-$

0.62

0.43

0.44

0.39

\section{$-$}

1.40

1.05

0.94

1.05

$-$

0.725

0.077

0.022

0.078

1.00

0.89

$-$

0.68

1.17

0.413

1.00

I. 15

0.84

0.72

I. 15

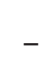

0.74

0.54

0.42

0.76

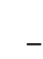

I.77

I. 32

I. 2 I

1.73

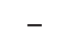

0.534

0.450

0.214

0.510

Palue

$-$

$-$

$-$

- 
Table I B (Continued)

\begin{tabular}{|c|c|c|c|c|c|c|c|c|}
\hline \multirow[t]{3}{*}{ Independent variable } & \multicolumn{8}{|c|}{ Extremely/very willing to comply with Isolation } \\
\hline & \multicolumn{4}{|c|}{ Unadjusted } & \multicolumn{4}{|c|}{ Adjusted } \\
\hline & OR & $95 \% \mathrm{Cl}$ & & $\mathbf{P}$ value & OR & $95 \% \mathrm{Cl}$ & & $P$ value \\
\hline \multicolumn{9}{|c|}{ Good self-rated health status } \\
\hline Yes & 1.00 & - & - & - & - & - & - & - \\
\hline No & 0.92 & 0.58 & 1.47 & 0.726 & - & - & - & - \\
\hline \multicolumn{9}{|l|}{ Marital status } \\
\hline Married & 1.00 & - & - & - & 1.00 & - & - & - \\
\hline Widowed & 0.80 & 0.54 & 1.18 & 0.261 & 0.78 & 0.51 & 1.19 & 0.246 \\
\hline Seperated/divorced & 0.99 & 0.65 & 1.51 & 0.968 & 0.98 & 0.64 & 1.53 & 0.946 \\
\hline Never married & 0.55 & 0.40 & 0.77 & $<0.001$ & 0.63 & 0.44 & 0.90 & 0.010 \\
\hline \multicolumn{9}{|c|}{ Pandemic influenza extremely/very likely } \\
\hline No & 1.00 & - & - & - & - & - & - & - \\
\hline Yes & 1.64 & 1.07 & 2.49 & 0.022 & - & - & - & - \\
\hline \multicolumn{9}{|c|}{$\begin{array}{l}\text { Extremely/very concerned for self/family } \\
\text { in event of pandemic influenza }\end{array}$} \\
\hline No & 1.00 & - & - & - & 1.00 & - & - & - \\
\hline Yes & 2.13 & 1.60 & 2.84 & $<0.001$ & 2.12 & 1.58 & 2.84 & $<0.001$ \\
\hline \multicolumn{9}{|c|}{$\begin{array}{l}\text { Life changes due to possibility } \\
\text { of pandemic influenza }\end{array}$} \\
\hline No & 1.00 & - & - & - & - & - & - & - \\
\hline Yes & 0.83 & 0.60 & 1.16 & 0.279 & - & - & - & - \\
\hline
\end{tabular}

Factors associated with lower levels of willingness to isolate oneself were speaking a language other than English at home, being younger and having never been married. These findings are potentially important for those involved in disease or emergency response, and with further research to identify reasons for this lack of willingness to isolate, may suggest a need for tailored communication or support strategies.

It is possible that these groups rely more on social contact outside of the household and, hence, would be less willing to forfeit this in the event of a pandemic. Indications in the data show that immigrants (those not born in Australia) and those who speak a language other than English at home may be less willing to isolate themselves.

Response to mask wearing was associated with the general factors of age, education, and concern for self/ family. However, it is the only behaviour studied here that is also associated with respondents' perceived likelihood of pandemic influenza occurring. Mask wearing, overall, is the behavior that people reported being least willing to comply with and it is possible that, for this reason, higher threat perception (concern and likelihood of pandemic) is required to drive compliance with this behavior. Younger people (16-24 and 25-34) are generally less willing to wear face masks, and only those with university qualifications or equivalent are significantly more likely to be willing to wear face masks. In the event of a pandemic it is likely that the public will be required to wear masks, especially in health care facilities, in public places, and in situations where individuals need to interface with the public, eg, certain critical occupations such as banking, welfare, post/delivery, fuel service, and shops. The mediating effect of increased threat perception in the event of actual pandemic is likely to raise compliance but data suggest that certain sectors of the general population are likely to remain resistant to mask wearing and require further encouragement, communication strategies, and education.

Our analysis indicates a number of significant differences between the levels of willingness to comply by respondents in differing marital status categories; most notably that those in the never married category report lower levels of willingness to comply. It should be noted, however, that there is a strong interaction with age, such that $52 \%$ of the never married category are in the 16-24 age range $(76 \%$ in 16-34) and therefore indications of lower willingness to comply may more simply be related to age than marital status. Similarly, $73 \%$ of those in the widowed category are in the $65+$ age ranges. 
Table IC Survey logistic modelling of extremely/very willing to wear a face mask: unadjusted and adjusted odds ratios (OR) Independent variable Extremely/very willing to wear a face mask

Unadjusted Adjusted

OR $\quad 95 \% \mathrm{Cl}$ P value

OR $\quad 95 \% \mathrm{Cl} \quad$ Pvalue

\section{Gender}

Male

Female

1.00

Location (defined by health region)

Urban

Rural

High psychological distress (K I 0 ? 22)

No

Yes

Age

16-24

25-34

$35-44$

$45-54$

$55-64$

65-74

$75+$

Children in household

No

Yes

Born in Australia

No

Yes

Speak language other than English

No

Yes

Living alone

No

Yes

Highest formal qualification

University degree/equivalent

TAFE certificate/Diploma

High school certificate

School certificate

None

Employed (paid or unpaid)

No

Yes

Household income (before tax)

$<A \$ 20 k$

A $\$ 20-40 \mathrm{k}$

A $\$ 40-60 \mathrm{k}$

$\mathrm{A} \$ 60-80 \mathrm{k}$

$>\mathrm{A} \$ 80 \mathrm{k}$
1.04

1.00

1.32

0.72

1.00

1.49

2.55

2.02

2.35

2.85

2.31

1.00

0.91

1.00

1.08

1.00

0.73

1.00

I.II

1.00

0.64

0.52

0.64

0.77

1.00

0.87

1.00

0.88

0.82

0.90

0.89
0.80

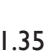

.35

0.770

$-$

I.04

1.68

0.023

0.45

1.16

0.183

- $\quad$ -

$0.86 \quad 2.57$

I.51 4.32

$1.24 \quad 3.30$

I.43 3.84

$1.75 \quad 4.65$

1.36

3.92

0.156

$<0.00$ I

0.005

0.001

$<0.00$ I

0.002

$-$

0.68

I.2I

0.519

0.79

1.46

0.637

0.49

1.07

0.110

0.86

1.42

0.428

$-\quad \quad-$

$\begin{array}{ll}0.44 & 0.92\end{array}$

$0.34 \quad 0.79$

$0.45 \quad 0.91$

0.91

I.21

$-$

0.017

0.002

0.014

0.251

0.49

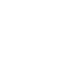

0.68

1.13

0.292

$-$

0.58

$-$

I. 34

0.54

1.26

1.50

I. 30

0.55
0.61

0.362

0.696

0.556
0.548

0.020

0.054

0.005

$<0.001$

0.020

$\begin{array}{llll}1.95 & \text { I.II } & 3.44 & 0.020\end{array}$

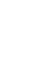$$
-
$$

$-$

$-$

$-$

$-$

$-$

$-$

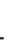


Table IC (Continued)

\begin{tabular}{|c|c|c|c|c|c|c|c|c|}
\hline \multirow[t]{3}{*}{ Independent variable } & \multicolumn{8}{|c|}{ Extremely/very willing to wear a face mask } \\
\hline & \multicolumn{4}{|c|}{ Unadjusted } & \multicolumn{4}{|c|}{ Adjusted } \\
\hline & OR & $95 \% \mathrm{Cl}$ & & $P$ value & OR & $95 \% \mathrm{Cl}$ & & P value \\
\hline \multicolumn{9}{|c|}{ Good self-rated health status } \\
\hline Yes & 1.00 & - & - & - & - & - & - & - \\
\hline No & 1.01 & 0.66 & 1.54 & 0.955 & - & - & - & - \\
\hline \multicolumn{9}{|l|}{ Marital status } \\
\hline Married & 1.00 & - & - & - & - & - & - & - \\
\hline Widowed & 0.96 & 0.66 & 1.38 & 0.808 & - & - & - & - \\
\hline Seperated/divorced & 0.95 & 0.66 & 1.39 & 0.804 & - & - & - & - \\
\hline Never married & 0.58 & 0.42 & 0.79 & 0.001 & - & - & - & - \\
\hline \multicolumn{9}{|c|}{ Pandemic influenza extremely/very likely } \\
\hline No & 1.00 & - & - & - & 1.00 & - & - & - \\
\hline Yes & 1.94 & 1.36 & 2.77 & $<0.001$ & $1.6 \mid$ & 1.09 & 2.36 & 0.016 \\
\hline \multicolumn{9}{|c|}{$\begin{array}{l}\text { Extremely/very concerned for self/family } \\
\text { in event of pandemic influenza }\end{array}$} \\
\hline No & 1.00 & - & - & - & 1.00 & - & - & - \\
\hline Yes & 1.92 & 1.47 & 2.52 & $<0.001$ & 1.78 & 1.34 & 2.37 & $<0.001$ \\
\hline \multicolumn{9}{|c|}{$\begin{array}{l}\text { Life changes due to possibility } \\
\text { of pandemic influenza }\end{array}$} \\
\hline No & 1.00 & - & - & - & - & - & - & - \\
\hline Yes & 0.96 & 0.69 & 1.32 & 0.792 & - & - & - & - \\
\hline
\end{tabular}

Worthy of mention are those factors included in the study and analysis that were not associated with willingness to comply with protective behaviors. No statistically significant effects were found for gender, those living alone, employment, or psychological distress. Gender and employment status have been identified as determinants of health protective behaviors in some studies, ${ }^{10,16}$ but were not found to be significant here.

Concern for self and family, has proven to be a significant factor associated with willingness to comply with protective health behaviors. This finding suggests that the concomitant concern/risk that would come with an actual pandemic might be sufficient to increase public health compliance to required levels, as noted in data from Hong Kong during SARS. ${ }^{18}$ An alternative, more active approach might include the use of risk communication messages before a pandemic occurs, or in the pre-pandemic/increased alert stages. Although the adoption of such an approach might seem compelling, Middaugh in a recent paper $^{23}$ warns about the unintended consequences of raising concern over 'frightening' the public about germs, increasing concern about seasonal influenza (to increase take-up of vaccination) and emphasizing the role of social distancing. He argues that such approaches cause societal estrangement and frighten health care workers, first responders, and those who would have contact with the public in the event of a pandemic.

Finally, consideration should be given to the limitations of the current study. The main limitation is that the questions are based on a hypothetical, anticipated threat to an influenza pandemic-naive population and, hence, serve as only a general indication of the likely response of the public to such an event. In addition, the analysis has focused on the use of dichotomized responses and has not included those who were less willing, but still may have complied with the behaviors investigated in the study. As noted, reported willingness to comply with these behaviors is likely to be mediated by a number of factors, and it is probable that only a subset of these have been identified in this study. The role of threat perception, anxiety, societal response (the compliance of others), media, and factors directly related to the course of the pandemic are all likely to influence public response.

\section{Conclusion}

Data from this study provide the first Australian population baseline in this area against which future response can be tracked and pandemic modeling can be informed. This study collected data regarding anticipated responses to an influenza pandemic and although in the event of an actual pandemic 
Table ID Survey logistic modelling of extremely/very willing - ALL behaviors: unadjusted and adjusted odds ratios (OR)

\begin{tabular}{|c|c|c|c|c|c|c|c|c|}
\hline \multirow[t]{3}{*}{ Independent variable } & \multicolumn{8}{|c|}{ Extremely/very willing - ALL behaviors } \\
\hline & \multicolumn{4}{|c|}{ Unadjusted } & \multicolumn{4}{|c|}{ Adjusted } \\
\hline & OR & $95 \% \mathrm{C}$ & & $\mathbf{P}$ value & OR & $95 \%$ & & P value \\
\hline \multicolumn{9}{|l|}{ Gender } \\
\hline Male & 1.00 & - & - & - & - & - & - & - \\
\hline Female & 0.95 & 0.74 & 1.22 & 0.680 & - & - & - & - \\
\hline \multicolumn{9}{|c|}{ Location (defined by health region) } \\
\hline Urban & 1.00 & - & - & - & - & - & - & - \\
\hline Rural & 1.22 & 0.96 & 1.54 & 0.098 & - & - & - & - \\
\hline \multicolumn{9}{|c|}{ High psychological distress (K I0 ? 22) } \\
\hline No & 1.00 & - & - & - & - & - & - & - \\
\hline Yes & 0.71 & 0.44 & 1.13 & 0.143 & - & - & - & - \\
\hline \multicolumn{9}{|l|}{ Age } \\
\hline $16-24$ & 1.00 & - & - & - & 1.00 & - & - & - \\
\hline $25-34$ & 1.41 & 0.79 & 2.50 & 0.241 & 1.24 & 0.68 & 2.27 & 0.477 \\
\hline $35-44$ & 2.04 & 1.18 & 3.54 & 0.011 & 1.75 & 1.00 & 3.06 & 0.051 \\
\hline $45-54$ & 2.24 & 1.34 & 3.76 & 0.002 & 1.98 & 1.17 & 3.38 & 0.012 \\
\hline $55-64$ & 2.25 & 1.35 & 3.76 & 0.002 & 1.95 & 1.15 & 3.30 & 0.013 \\
\hline $65-74$ & 2.71 & 1.63 & 4.51 & $<0.001$ & 2.34 & 1.39 & 3.96 & 0.001 \\
\hline $75+$ & 2.37 & 1.37 & 4.09 & 0.002 & 1.82 & 1.03 & 3.23 & 0.041 \\
\hline \multicolumn{9}{|l|}{ Children in household } \\
\hline No & 1.00 & - & - & - & - & - & - & - \\
\hline Yes & 1.02 & 0.77 & 1.35 & 0.908 & - & - & - & - \\
\hline \multicolumn{9}{|l|}{ Born in Australia } \\
\hline No & 1.00 & - & - & - & - & - & - & - \\
\hline Yes & 1.19 & 0.89 & 1.60 & 0.250 & - & - & - & - \\
\hline \multicolumn{9}{|c|}{ Speak language other than English } \\
\hline No & 1.00 & - & - & - & 1.00 & - & - & - \\
\hline Yes & 0.57 & 0.38 & 0.85 & 0.006 & 0.62 & 0.40 & 0.95 & 0.029 \\
\hline \multicolumn{9}{|l|}{ Living alone } \\
\hline No & 1.00 & - & - & - & - & - & - & - \\
\hline Yes & 1.07 & 0.84 & 1.37 & 0.572 & - & - & - & - \\
\hline \multicolumn{9}{|l|}{ Highest formal qualification } \\
\hline University degree/equivalent & 1.00 & - & - & - & - & - & - & - \\
\hline TAFE certificate/Diploma & 0.69 & 0.49 & 0.99 & 0.044 & - & - & - & - \\
\hline High school certificate & 0.60 & 0.40 & 0.90 & 0.013 & - & - & - & - \\
\hline School certificate & 0.64 & 0.45 & 0.90 & 0.010 & - & - & - & - \\
\hline None & 0.68 & 0.43 & 1.06 & 0.085 & - & - & - & - \\
\hline \multicolumn{9}{|l|}{ Employed (paid or unpaid) } \\
\hline No & 1.00 & - & - & - & - & - & - & - \\
\hline Yes & 0.93 & 0.73 & 1.19 & 0.576 & - & - & - & - \\
\hline \multicolumn{9}{|c|}{ Household income (before tax) } \\
\hline$<\mathrm{A} \$ 20 \mathrm{k}$ & 1.00 & - & - & - & - & - & - & - \\
\hline $\mathrm{A} \$ 20-40 \mathrm{k}$ & 0.91 & 0.61 & 1.35 & 0.624 & - & - & - & - \\
\hline $\mathrm{A} \$ 40-60 \mathrm{k}$ & 0.76 & 0.50 & 1.14 & 0.181 & - & - & - & - \\
\hline $\mathrm{A} \$ 60-80 \mathrm{k}$ & 0.89 & 0.54 & 1.47 & $0.64 I$ & - & - & - & - \\
\hline$>A \$ 80 k$ & 1.10 & 0.76 & 1.60 & 0.606 & - & - & - & - \\
\hline
\end{tabular}


Table ID (Continued)

\begin{tabular}{|c|c|c|c|c|c|c|c|c|}
\hline \multirow[t]{3}{*}{ Independent variable } & \multicolumn{8}{|c|}{ Extremely/very willing - ALL behaviors } \\
\hline & \multicolumn{4}{|c|}{ Unadjusted } & \multicolumn{4}{|c|}{ Adjusted } \\
\hline & OR & $95 \% \mathrm{Cl}$ & & $P$ value & OR & $95 \% \mathrm{C}$ & & $P$ value \\
\hline \multicolumn{9}{|c|}{ Good self-rated health status } \\
\hline Yes & 1.00 & - & - & - & - & - & - & - \\
\hline No & 0.85 & 0.56 & 1.27 & 0.419 & - & - & - & - \\
\hline \multicolumn{9}{|l|}{ Marital status } \\
\hline Married & 1.00 & - & - & - & - & - & - & - \\
\hline Widowed & 0.84 & 0.59 & 1.18 & 0.308 & - & - & - & - \\
\hline Seperated/divorced & 0.93 & 0.65 & 1.32 & 0.673 & - & - & - & - \\
\hline Never married & 0.51 & 0.37 & 0.70 & $<0.001$ & - & - & - & - \\
\hline \multicolumn{9}{|c|}{ Pandemic influenza extremely/very likely } \\
\hline No & 1.00 & - & - & - & - & - & - & - \\
\hline Yes & 1.41 & 0.99 & 2.00 & 0.055 & - & - & - & - \\
\hline \multicolumn{9}{|c|}{$\begin{array}{l}\text { Extremely/very concerned for self/family } \\
\text { in event of pandemic influenza }\end{array}$} \\
\hline No & 1.00 & - & - & - & 1.00 & - & - & - \\
\hline Yes & 2.11 & 1.62 & 2.73 & $<0.001$ & 2.03 & 1.56 & 2.64 & $<0.001$ \\
\hline \multicolumn{9}{|c|}{$\begin{array}{l}\text { Life changes due to possibility } \\
\text { of pandemic influenza }\end{array}$} \\
\hline No & 1.00 & - & - & - & - & - & - & - \\
\hline Yes & 1.06 & 0.77 & 1.45 & 0.727 & - & - & - & - \\
\hline
\end{tabular}

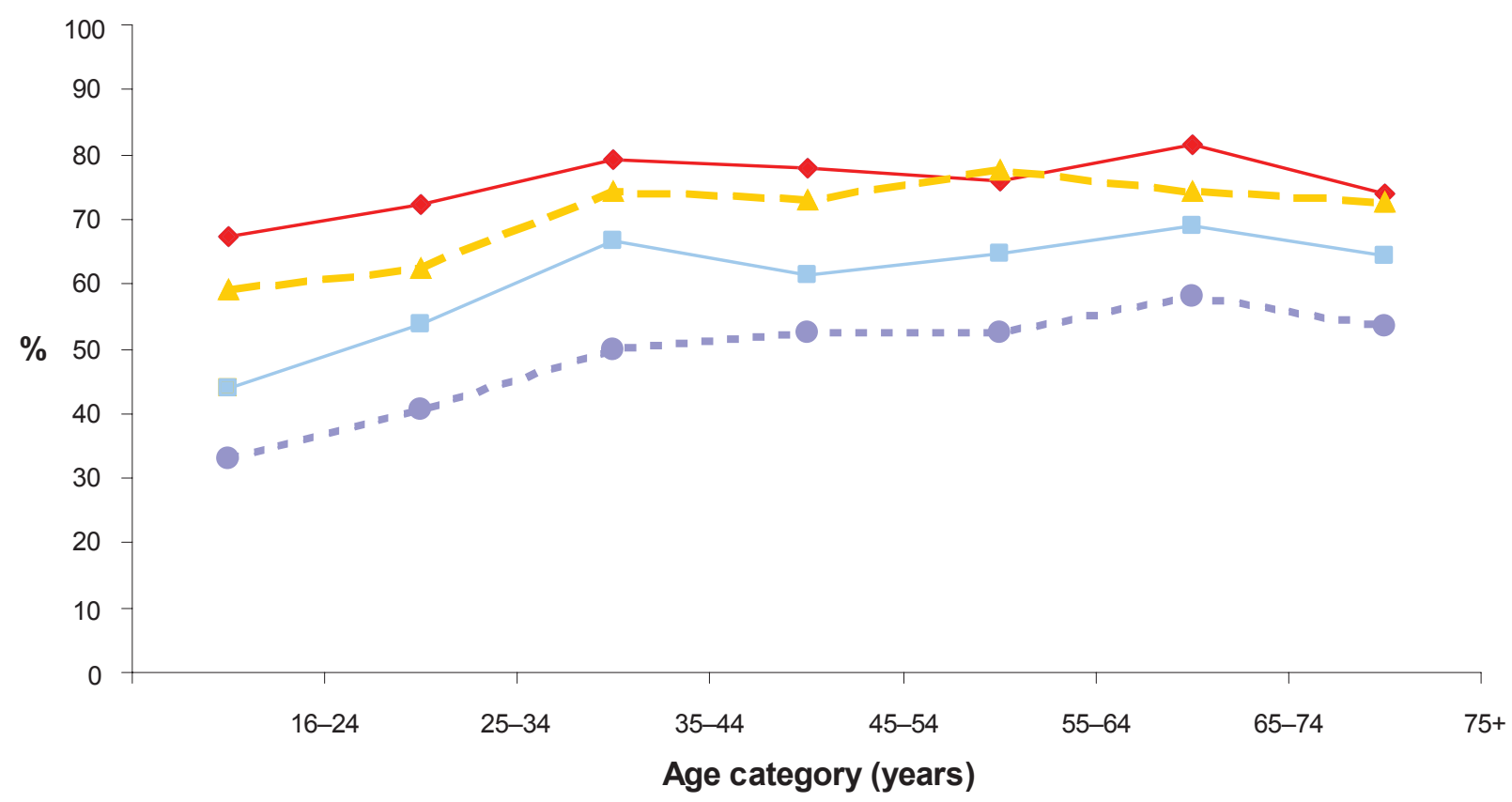

$\longrightarrow$ Receive vaccination $\_\_$Isolate if needed $\_-$Wear face mask $=-\sim$ Comply with all

Figure I The influence of age on willingness to comply with health protective behaviors. Percentage shown is the proportion 'very'/'extremely' willing to comply. 
the overall level of compliance is likely to be influenced by a range of factors, it is probable that relative compliance levels within the data would be upheld and would be more robust for use in pandemic planning.

\section{Acknowledgments}

This study was funded by Emergency Management Australia. We would like to acknowledge the assistance of NSW Health staff in the Centre for Epidemiology and Research for their help with field testing, data gathering, and statistical support.

\section{Disclosure}

The authors report no conflicts of interest in this work.

\section{References}

1. Jefferson T, Foxlee R, Del Mar C, et al. Physical interventions to interrupt or reduce the spread of respiratory viruses: systematic review. BMJ. 2008;336:77-80.

2. Australian Government. Australian Health Management Plan for Pandemic Influenza. Canberra: Australian Government, Department of Health and Ageing. Commonwealth of Australia; 2006.

3. NSW Health. NSW Health interim influenza state action plan. 2005. [Cited Oct 13, 2008.] Available from: http://www.health.nsw.gov. au/pubs/2005/pdf/pandemic_ap.pdf.

4. World Health Organization. Guidelines for the use of seasonal influenza vaccine in humans at risk of H5N1 infection. Jan 30, 2004. [Cited Oct 13, 2008.] Available from: http://www.who.int/csr/disease/ avian_influenza/guidelines/seasonal_vaccine/en/.

5. Sim K, Chua HC. The psychological impact of SARS: A matter of heart and mind. CMAJ. 2004;170:811-812.

6. Lau JTF, Yang X, Pang E, Tsui HY, Wong E, Wing YK. SARS-related perceptions in Hong Kong. Emerg Infect Dis. 2005;11:417-424.

7. Quah SR, Hin-Peng L. Crisis prevention and management during SARS outbreak, Singapore. Emerg Infect Dis. 2004;10:364-368.

8. DiGiovanni C, Conley J, Chiu D, Zaborski J. Factors influencing compliance with quarantine in Toronto during the 2003 SARS outbreak. Biosecur Bioterror. 2004;2:265-272.

9. Cava MA, Fay KE, Beanlands HJ, McCay EA, Wignall R. Risk perception and compliance with quarantine during the SARS outbreak. J Nurs Scholarsh. 2005;37:343-347.
10. Lau JTF, Kim JH, Tsui HY, Griffiths S. Anticipated and current preventative behaviors in response to an anticipated human-to-human H5N1 epidemic in Hong Kong Chinese general population. BMC Infect Dis. 2007;7:18. doi:10.1186/1471-2334-7-18.

11. Lau JTF, Kim JH, Tsui HY, Griffiths S. Perceptions related to human avian influenza and their associations with anticipated psychological and behavioural responses at the onset of outbreak in the Hong Kong Chinese general population. Am J Infect Control. 2007;35:38-49.

12. Kristiansen IS, Halvorsen PA, Gyrd-Hansen D. Influenza pandemic: perception of risk and individual precautions in a general population. Cross sectional study. BMC Public Health. 2007;7:48.

13. Di Giuseppe G, Abbate R, Albano L, Marinelli P, Angelillo IF. A survey of knowledge, attitudes and practices towards avian influenza in an adult population of Italy. BMC Infect Dis. 2008;8:36. Doi: 10.1186/14712334-8-36.

14. Gaglia MA, Cook RL, Kraemer KL, Rothberg MB. Patient knowledge and attitudes about avian influenza in an internal medicine clinic. Public Health. 2008;122:462-470.

15. Sadique MZ, Edmunds WJ, Smith RD, et al. Precautionary behavior in response to perceived threat of pandemic influenza. Emerg Infect Dis. 2007;13:1307-1313.

16. Leung GM, Lam TH, Ho LM, et al. The impact of community psychological responses on outbreak control for severe acute respiratory syndrome in Hong Kong. J Epidemiol Community Health. 2003;57:857-863.

17. Lau JTF, Kim JH, Tsui HY, Griffiths S. Perceptions related to birdto-human avian influenza, influenza vaccination, and use of face mask. Infection. 2008;36:434-443.

18. Lau JTF, Yang X, Tsui H, Kim JH. Monitoring community responses to the SARS epidemic in Hong Kong: from day 10 to day 62. J Epidemiol Community Health. 2003;57:864-870.

19. Wilson D, Lester R, Taylor A, et al. Prevalence of influenza immunization in Australia and suggestions for future targeting of campaigns. Soz Präventivmed. 2002;47:91-99.

20. Kessler RC, Andrews G, Colpe LJ, et al. Short screening scales to monitor population prevalences and trends in non-specific psychological distress. Psychol Med. 2002;32:959-976.

21. Centre for Epidemiology and Research. 2007 Report on Adult Health from the New South Wales Population Health Survey. [Cited Oct 18, 2008.] Sydney, Australia: New South Wales Department of Health; 2008.

22. Barr M, Raphael B, Taylor M, et al. Pandemic influenza in Australia: perceptions of threat and preparedness to comply. BMC Infect Dis. 2008;8:117.

23. Middaugh JP. Pandemic influenza preparedness and community resiliency. JAMA. 2008;299:566-568. 